Bulletin d'études orientales

LXIV | 2016

Histoire et anthropologie des odeurs en terre d'Islam à l'époque médiévale - Année 2015

\title{
Des parfums et des fumées : les parfums à brûler en Islam médiéval
}

Jean-Charles Ducène

\section{OpenEdition}

\section{Journals}

Édition électronique

URL : https://journals.openedition.org/beo/4693

DOI : $10.4000 /$ beo.4693

ISSN : 2077-4079

Éditeur

Presses de l'Institut français du Proche-Orient

Édition imprimée

Date de publication : 1 avril 2016

Pagination : 159-178

ISBN : 978-2-35159-800-9

ISSN : 0253-1623

Référence électronique

Jean-Charles Ducène, «Des parfums et des fumées : les parfums à brûler en Islam médiéval ». Bulletin d'études orientales [En ligne], LXIV | 2016, mis en ligne le 01 avril 2018, consulté le 21 septembre 2021. URL : http://journals.openedition.org/beo/4693 ; DOI : https://doi.org/10.4000/beo.4693 


\title{
Des parfums et des fumées : les parfums à brûler en Islam médiéval
}

\author{
Jean-Charles DucÈNE
}

Résumé : Par la rareté des sources, il est difficile d'identifier les usages des fumigations dans le premier siècle de l'Islam, mais à partir de la période abbasside, les substances et les usages deviennent plus clairs. Ainsi, à côté de l'encens apparaissent de nouveaux produits originaires d'Asie, comme le musc, le bois de santal, l'agalloche et le camphre. L'élite sociale brûle ces essences pour parfumer ses vêtements ou durant des réunions festives fort marquées socialement. Quant à la médecine, elle cantonne les fumigations à des fins prophylactiques (purification de l'air) ou thérapeutiques. Dans le domaine des pratiques religieuses, ce sont le soufisme et les pèlerinages secondaires qui en développent réellement l'usage.

Mots-clés : odeur, parfum, médecine, sociabilité.

\begin{abstract}
Since there is not enough documentation, it is difficult to identify the functions of the fumigations in the first century of the Medieval Islam, but from the Abbasid period the substances and the uses become clearer. Besides the incense, we also find natural products coming from Asia (e.g. musk, sandalwood, wood of the agarwood and camphor). The social elite burns these scents to perfume its linen and during festive events. As for the fumigations in the medicine, they are adopted for prophylactic (air purification) and therapeutic purposes. In the religious field, Sufism and the popular pilgrimages spread the use of incense.
\end{abstract}

Keywords: smell, fragrance, healthcare, sociability.

$$
\begin{aligned}
& \text { الملخص : تتناول هذه المقالة استعمال التبخير في العصور الوسطى الإِسلامية. بسبب قلّة المصادر }
\end{aligned}
$$

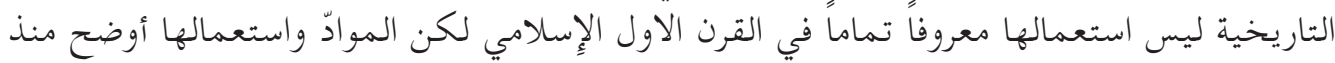

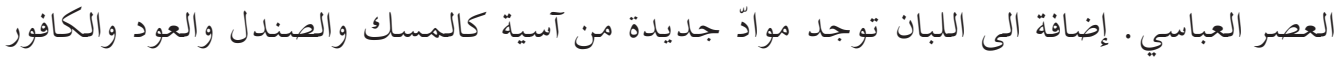

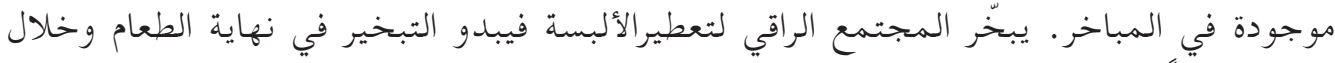

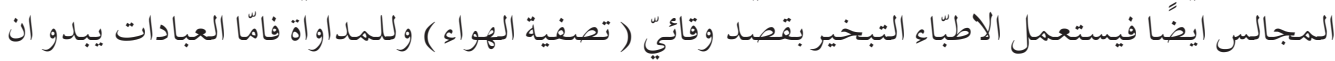

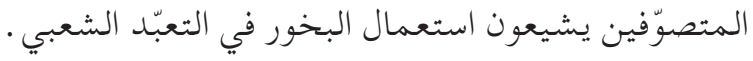

$$
\begin{aligned}
& \text { الكلمات المحوريّة : اجتماعية، طب، عطر، رائحة. }
\end{aligned}
$$


Si les parfums sont largement en usage dans le Proche-Orient médiéval, et ceci en continuité avec les pratiques antiques, des changements dans la nature des substances utilisées sont observables ${ }^{1}$. On constate ainsi une certaine prédominance des produits naturels provenant d'Asie au cours de la période concernée, concurremment avec un désintérêt pour d'autres matières locales, comme le nard par exemple. Qu'en est-il cependant des fumigations, ces matières expressément recherchées car leur combustion libère des fumées odorantes? Le sud de l'Arabie est certes le pays de l'encens, mais l'usage de ces fumeroles comme celles d'autres résines a-t-il connu une évolution spécifique?

Pour l'époque préislamique, les informations sur l'emploi de l'encens à La Mecque sont si rares qu'il est difficile d'en cerner réellement l'usage à l'aube de l'Islam. Un rite d'encensement de la Ka'ba à l'époque préislamique ${ }^{2}$ est vraisemblable car c'est lui qui aurait mis le feu à la Ka'ba durant la jeunesse du prophète. Dans ce cas, il s'agirait plutôt de bois d'agalloche ${ }^{3}$. Cette fumigation se maintient même jusqu'à l'époque d'Ibn al-Zubayr (m. 72/692). Par ailleurs, l'encensement des morts était également connu à l'époque préislamique (DE GOEJE 1907 à Médine) et cette pratique a sans doute perduré par la suite car elle est désapprouvée par l'islam naissant. Michael Jan De Goeje a ainsi attiré l'attention sur des dispositions testamentaires de certains personnages cités dans les Ṭabaqāt d'Ibn Sa'd (m. 230/845) qui l'interdisent. Le shaféite al-Nawāwī (m. 676/1277) désapprouve cet usage de faire brûler de l'encens devant le cortège ou à côté du mort sans en donner la raison, ce qui indique bien que cela était encore pratiqué ${ }^{4}$. D'ailleurs, les quatre écoles juridiques sont loin d'être unanimes sur la question de faire brûler de l'encens près du mort, après les ablutions funéraires ${ }^{5}$.

Cependant, dans le rapport aux bonnes odeurs, l'exemple du prophète a été important car l'image que l'on en a gardée est celle de quelqu'un qui appréciait et approuvait l'usage ${ }^{6}$ des parfums ${ }^{7}$.

\section{Une littérature spécialisée rare}

La littérature médiévale sur le sujet des parfums n'est guère diversifiée. Les ouvrages de Théophraste comme l'Enquête sur les plantes et À propos des odeurs n'étaient pas connus des Arabes. Seul le second a été traduit à la fin du Moyen Âge et ne semble pas avoir exercé beaucoup d'influence ${ }^{8}$.

1. LEV et ZOHAR 2013, p. 11-30.

2. GAUdeFroy-DeMOMBYNES 1923, p. 33 ; CRONE 1987, p. 52.

3. CRONE 1987, p. 75.

4. Al-Nawāwī, Minhāăğ al-țālibīn, I, p. 223.

5. Al-Ǧazīrī, Kitāb al-figh, I, p. 507.

6. Cette inclination a même été prise très au sérieux par Ibn Sīnā, qui a laissé une Risāla fì-l-țib qui en traite (Мicнот 1978).

7. Al-Buhārī, Les traditions islamiques, I, p. 413-414 et IV, p. 126-128.

8. LEVEY 1973, p. 19. 
Le médecin chrétien Ibn Masawayh (m.243/857) a composé le Kitāb ğawāhir al-țīb al-mufrada ${ }^{9}$. Il s'agit d'un petit traité qui donne une énumération de vingt-huit substances servant à la composition des parfums. L'auteur indique leurs provenances, leurs particularités et aussi leurs usages médicaux, mais il ne précise pas les procédés de fabrication. En revanche, Ya'qūb ibn Ishạa al-Kindī (m. 256/870) dans le Kitāb kìmiyā' al-ițr wa-l-taṣî̀dàt donne cent-sept recettes pour préparer des huiles, des pommades et des parfums et traite aussi de leur commerce ${ }^{10}$. L'ouvrage est divisé en huit chapitres abordant la fabrication de différents parfums (musc, ambre, safran, wars, camphre, huiles et mélanges de type ġāliya, sukk, rāmik) et l'obtention de plusieurs distillats (tașì̄dāt). Entre ces chapitres, des recettes d'autres parfums sont mentionnées.

Au siècle suivant, le médecin Muhammad al-Tamīmī (fl. 370/970) compose le Kitāb habīb al-'arūs wa-rayḥān al-nufūs, où il donne plus de trois-cent-dix préparations ${ }^{11}$. L'auteur était originaire de Jérusalem et il fut l'élève de son grand-père, Sa'īd, également médecin. Il exerça cet art auprès du gouverneur de Ramla, Hasan ibn 'Ubayd Allah ibn Țugğ et se retrouva en Égypte en suivant Ya'qūb ibn Killis (m. 380/991), le vizir d'al-Mu'izz (m. 365/979) et d'al-'Azīz (m. 386/996). Selon le manuscrit unicum, incomplet, conservé à Téhéran (Bibliothèque du Parlement, Mağlis-i Šurā), les principaux produits réalisés sont de la teinture (șibāj) parfumée, de l'huile (duhn), de l'eau aromatisée (gisla), des lotions parfumées pour les cheveux (lahllaha) comme le définit lui-même l'auteur, des composés particuliers (nadūh, mahlab, șayyāh. ${ }^{12}$ ), des distillats (tașî̀), des grains (habb), des mélanges de cendres de plantes (ušnān) ${ }^{13}$, de la poudre (ㅁurīra), de l'eau parfumée, du jus ('așīr), du suc ('aqìd), des produits réalisés après immersion (tahmīir) d'une substance et des onguents (marham). Sans être exhaustive, cetteliste montre l'ampleur des produits parfumés fabriqués et leur emploi varié. Muhammad al-Tamīmī rassemble les recettes ${ }^{14}$ de fabrication à partir d'ouvrages antérieurs mais il indique régulièrement pour quel calife ou quel personnage le parfum a été réalisé. L'auteur est aussi cité plus tard par Ibn al-Bayțār (m. 646/1248),

9. Ibn Masawayh, Kitāb ğawāhir al-țīb al-mufrada, p. 5-27.

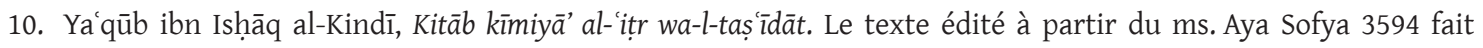
59 pages en tout.

11. Al-Tamīmī, Kitāb habīb al-'arūs wa-rayḥān al-nufūs. Il s'agit d'une reproduction du ms. de Téhéran, Mağlis-i Šurā 2294. Biographie de l'auteur dans Ibn Abī Ușaybi a, 'Uyūn al-anbā' fí țabaqāt al-ațibbā', p. 546-547 et Ibn al-Qifțī, Tārīh al-hukamā', p. 105-106.

12. Al-Fīrūzābādī le définit simplement comme un type de parfum ou de lotion, sans en donner la composition, Al-qāmūs al-muhịț, p. 256.

13. Al-Kindī, Medical Formulary, p. 231.

14. Il faut reconnaître que l'identification certaine des produits premiers comme leur pondération restent difficiles à établir, ce qui rend ces recettes délicates à reconstituer. 
notamment pour les huiles composées, et al-Nuwayrī ${ }^{15}$ (m. 733/1333) lui fait d'importants emprunts dans le chapitre sur la préparation des parfums.

Enfin, al-Suyūṭi (m.911/1505) compose al-Maqāma al-miskiyya ${ }^{16}$ mais ce traité appartient à la production en prose rimée d'al-Suyūṭi où l'auteur montre d'abord sa maîtrise de la langue, et n'informe pas sur l'usage réel des parfums. Ainsi, quatre « princes des parfums » demandent l'arbitrage d'un « imam en éloquence » pour que celui-ci désigne la fragrance qui aurait la préséance. Il expose finalement leurs qualités respectives, ces quatre parfums étant respectivement le musc, l'ambre, le safran et le musc de civette.

Quoique l'origine des substances nous amènerait à croire que les ouvrages de botanique et plus rarement de zoologie constitueraient des sources d'informations importantes, leur consultation montre qu'il n'en est rien. Dans le meilleur des cas, ils indiquent simplement l'usage de la fumée ${ }^{17}$. Enfin, la médecine médiévale (SANAGUSTIN 1998), héritière en cela de la médecine hellénistique mais aussi indienne, considère également les parfums, quelle que soit leur forme, comme ayant un effet sur la physiologie, ce qui conduit à interroger aussi cette littérature.

\section{Les mots et les substances}

La terminologie arabe médiévale ne permet pas d'identifier avec facilité et certitude toutes les substances qui étaient considérées comme odoriférantes ${ }^{18}$. Ainsià côté des termes généraux comme țīb (bonne odeur, parfum), 'ịtr (parfum) et rayḥān, pl. rayāhīn (plante odoriférante), on trouve la dénomination d'un grand nombre de substances spécifiques provenant des végétaux et des animaux, entrant dans la composition des parfums, et qui doivent être parfois brûlées pour libérer leur odeur.

Parmi les substances végétales ${ }^{19}$, les résines nous intéressent en premier lieu, avec d'abord l'encens. Le terme lubān est synonyme du persan kundur et désigne la résine séchée

15. Al-Nuwayrī, Nihāyat al-arab fï funūn al-adab, 2004, vol. 12, p. 3-83 (WIEDEMANN 1913 et pour une traduction partielle WIEDEMANN 1970a). Le texte d'al-Nuwayrī porte essentiellement sur l'origine et la description des substances plutôt que sur les recettes de parfums. Il s'arrête néanmoins sur six parfums : le musc, l'ambre, le bois d'agalloche, le santal, le nard (sunbul) et le costus (qust). Précisons que les origines asiatiques des produits sont souvent précisées par des citations d'al-Ya'qūbī qu'il lit chez al-Tamīmī.

16. Al-Suyūțī, Al-Maqāma al-miskiyya, p. 189-202.

17. DIETRICH 1988, I, p. 19.

18. En l'absence d'un dictionnaire historique de l'arabe, nous nous sommes limité à interroger le Lisān al-'Arab d'Ibn Manẓūr (m. 711/1311) et le Muhịt d'al-Fīrūzābādī (m. 811/1415), en sachant que le premier donne souvent une série de citations qui permettent de dresser un semblant de chronologie des acceptions. Par ailleurs, il est à souligner que dès le Kitāb al-nabāt d'Abū Ḥanīfa al-Dīnawarī (m. av. 290/902-903), la terminologie des substances odoriférantes apparaît stabilisée. Une étude lexicale qui couvrirait leurs occurrences durant les VII ${ }^{\mathrm{e}}$ et VIII ${ }^{\mathrm{e}}$ siècles serait profitable pour cerner la période d'apparition de tel ou tel mot.

19. MIQUEL 1980, p. 423-424. 
de l'arbre à encens (Boswellia sacra) ${ }^{20}$. Certains auteurs ajoutent parfois l'adjectif « blanc » pour le distinguer d'autres résines comme le styrax (may'a, Styrax officinalis) ${ }^{21}$ ou d'autres encore provenant d'Asie du Sud-Est comme le benjoin (Styrax benzoin) qui ont une autre couleur. Quant à la myrrhe (murr) ${ }^{22}$, c'est une gomme qui suinte du Commiphora myrhha, arbrisseau que l'on trouve au Proche-Orient. Le camphre (käfür) ${ }^{23}$ dont le nom d'origine indienne (sanskrit: karpūram) indique que le produit provient de l'Asie du Sud-Est, voit son usage se répandre au Proche-Orient sous l'islam. Mūsā ibn Rabāḥ al-Awsī al-Sīrāfī, au $\mathrm{X}^{\mathrm{e}}$ siècle, donne la plus ancienne description arabe de sa récolte à Sumatra ${ }^{24}$. Al-Qazwīnī (m. 682/1283) ajoute l'acacia (umm ġaylān) provenant de l'Acacia arabica et le baume (balasān) de Judée, recueilli du Commiphora opobalsamum que l'on peut utiliser en fumigation ${ }^{25}$. La Méditerranée, plus précisément l'île de Chios, fournit du mastic (maștaka) ${ }^{26}$ ou résine grecque (al-illk al-rūmì), sécrétion du Pistacia lentiscus. Si cette gomme est utilisée sous plusieurs formes en pharmacopée, Abū Hanīfa al-Dīnawarī ${ }^{27}$ (m. av. 290/902-903) en cite explicitement l'usage en duhn, "en fumée ». En revanche, la sandaraque (sandarūs) ${ }^{28}$, une résine produite par le cyprès de l'Atlas, est souvent utilisée en fumigation. Enfin, la Crète donne le ladanum (lādan) ${ }^{29}$ produit par les cistes. Si ces deux gommes sont utilisées sous plusieurs formes en pharmacopée, elles sont parfois aussi brûlées.

À coté des résines végétales, le bois ou l'écorce de certains arbres ou arbustes peuvent également être brûlés. Parmi ceux-ci figure le bois de șandal ou santal ${ }^{30}$ dont l'étymon (sanskrit: čandana) montre que le produit est indien. Le terme désigne trois essences différentes, dont les produits (huiles) sont surtout indiqués en médecine. On mentionne très souvent le ' $\bar{u} d{ }^{31}$ ou bois d'agalloche (Aquilaria malacensis Lamk. et l'Agallocha Roxb.) ou bois d'aigle ou aussi bois d'aloès par extension. Ce développement sémantique est cependant source de confusion car l'aloès véritable, șabr, n'a qu'un usage médical, n’entrant pas

20. DiETRICH 1983 ; al-Idrīsī, Kitāb al-ğāmi' li-șifāt aštāt al-nabāt, I, p. 213 et II, p. 253 ; Ibn al-Bayțār, Traité des simples, III, p. 200-204.

21. Al-Idrīsī, Kitāb al-ğāmi li-șifāt aštāt al-nabāt, I, p. 275 et II, p. 320 ; Ibn al-Bayțār, Traité des simples, III, p. 350-352.

22. Al-Idrīsī, Kitāb al-ğāmi li-șifāt aštāt al-nabāt, I, p. 263 et II, p. 307 ; Ibn al-Bayțār, Traité des simples, III, p. $300-303$.

23. Al-Idrīs̄ī, Kitāb al-ǧāmi li-șifāt aštāt al-nabāt, I, p. 231 et II, p. 276 ; Ibn al-Bayțār, Traité des simples, III, p. 127-131 ; DoNKIN 1999, p. 140-143.

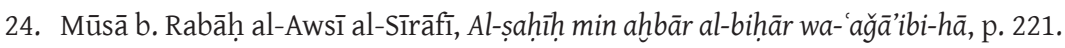

25. Al-Qazwīnī, El Libro de las plantas, p. 42 et p. 45 ; al-Idrīs̄ī, Kitāb al-ǧāmic li-șifāt aštāt al-nabāt, I, p. 44 et II, p. 69.

26. Al-Idrīsī, Kitāab al-ǧāmic li-șifāt aštāt al-nabāt, I, p. 265 et II, p. 310 ; Ibn al-Bayțār, Traité des simples, III, p. 323-325 : Al-F̄irūzābādī, Al-qāmūs al-muhīị, p. 967.

27. Al-Dīnawarī, The book of plants, p. 92.

28. Ibn al-Bayțār, Traité des simples, II, p. 297-298. Al-Bīrūnī le fait venir du pays des Zanǧ, (al-Bīrūnī, Kitāb al-ṣaydana fi-l-țibb, p. 353). Le sandarūs est parfois confondu avec l'ambre jaune, (KÄs 2010, II, p. 707-710).

29. Al-Idrīsī, Kitāb al-ǧămi li-șifāt aštāt al-nabāt, I, p. 243-244 et II, p. 286.

30. Ibn al-Bayțār, Traité des simples, II, p. 383-384.

31. Ibn al-Bayțār, Traité des simples, II, p. 484-485 ; al-Fīrūzābādī, Al-qāmūs al-muhịț, p. 327 ; Ibn Manẓūr, Lisān, VIII, p. 160, à l'entrée ț.r.y. ; al-Bīrūnī, Kitāb al-șaydana fī-l-țibb, p. 444 : l'auteur mentionne des mélanges avec l'ambre et le musc à mettre à brûler. 
dans les fumigations. Al-Fīrūzābādī (m. 811/1415) mentionne expressément le 'ū comme substance à brûler (bahūur) en précisant qu'il peut remplacer l'encens. Bien souvent, le terme général est accompagné d'une nisba qui en spécifie l'origine géographique. Ibn Manzūr (m. 711/1311) a conservé l'acception particulière de 'ùd muțarrā soit «bois trempé dans une eau parfumée et destiné à être brûlé en guise d'encens ». Quant au bān ${ }^{32}$ (Moringa peregrina), c'est une huile employée depuis l'Antiquité en médecine, mais il ne semble pas qu'elle ait été brûlée. Al-Idrīsī identifie une plante particulière, le bahūr al-sūdāniyya, comme étant très odoriférante quand elle est jetée au feu ${ }^{33}$. Elle sert surtout contre le rhume.

Les substances essentielles qui relèvent du monde animal sont le musc (misk, du sanskrit muṣka) ${ }^{34}$, l'ambre ('anbar ou Physeter catodam) ${ }^{35}$ et les azfā̄r al-țīb (litt. « les rognures du parfum ») ou blattes de Byzance qui étaient utilisées en fumigation et en parfum ${ }^{36}$. Le premier provient de la chèvre musquée (Moschus cupreus) d'Asie centrale (AKAsoY et Yoeli-TlaLim 2007 ; King 2010), dont al-Mas ū $\mathrm{d} \overline{1}$ (m. 345/956) explique comment les Chinois et les Tibétains prélèvent la substance ${ }^{37}$. Le sac ou la vésicule de l'animal qui contient la précieuse sécrétion s'appelle nāfiğa (du persan nāfah) et se retrouve aussi mentionné dans les listes de cadeaux de luxe ${ }^{38}$. Il faut le distinguer du musc de civette (zabād). Quant à l'ambre gris, à différencier de l'ambre jaune (kahrubā') qui est une résine végétale fossile - le succin -, son origine maritime et animale est mentionnée au début du X $\mathrm{X}^{\mathrm{e}}$ siècle par Abū Zayd al-Sīrāfī ${ }^{39}$. Il est probable que le terme arabe ait été emprunté au pehlevi avant de passer ensuite en hébreu médiéval, en ge'ez, en syriaque et en grec byzantin ( $\alpha \mu \pi \alpha \rho$ à ne

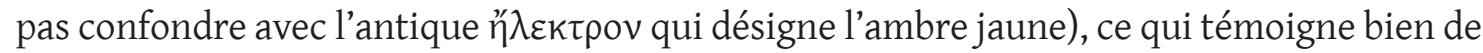
la diffusion du produit. Les blattes de Byzance sont de petites membranes contenues dans divers mollusques univalves (MCHUGH 2013).

Le manuel commercial de Ǧafar b. 'Alī al-Dimašqī ( $\mathrm{V}^{\mathrm{e}}-\mathrm{VI}^{\mathrm{e}} / \mathrm{XI}^{\mathrm{e}}-\mathrm{XII}{ }^{\mathrm{e}}$ siècle), le Kitāb al-išāra ilā maḥāsin al-tiǧāra, qui appartenait sans doute au monde fatimide, énumère vingtdeux substances, en précisant parfois leur usage comme tīb ou comme adwiya, par exemple pour le 'ūd et le șandal ${ }^{40}$. Et il n'y a rien d'étonnant à retrouver énumérées ces essences

32. AUBAIL-SALLENAVE 1998. Le terme est polysémique et recouvre onze arbres ou végétaux.

33. Al-Idrīsī, Al-ǧāmi li-șifāt al-nabāt, I, p. 62-63.

34. Cette étymologie traditionnelle semble poser problème auprès des indianistes car ce terme sanskrit qui a pour sens « testicule » ne semble pas avoir désigné le musc dans les langues indiennes (King 2007, p. 28-34).

35. Le Caire mamelouke a eu un marché de l'ambre, dans un bâtiment particulier, distinct du sūq al-'atțārīn, voir RAYMOND et WIET 1979, p. 192-193.

36. Ibn al-Bayțār, Traité des simples, I, p. 95-96.

37. Al-Mas'ū $\mathrm{d} \overline{1}$, Les prairies d'or, I, p. 143-144 ; Ibn al-Bayțār, Traité des simples, III, p. 316-319.

38. Al-Qaddūmī, Book of Gifts and Rarities, p. 121.

39. Reinaud, Relation des voyages faits par les Arabes et les Persans dans l'Inde et la Chine, II, p. 138-141 ; Ibn al-Bayțār, Traité des simples, II, p. 469-471; RUSKA et PLESSNER 1960 ; voir dans ce volume : BUQUET 2015.

40. Al-Dimašq̄̄, Kitāb al-išāra ilā mahāāin al-tiğāra, p.31-37. Le texte a été traduit par Eilhard Wiedemann (WIEDEMANN 1970). Voir aussi al-Ǧāhiz, Kitāb al-tabașșur bi-l-tiǧāra, p. 157 et p. 159. 
odorantes dans les trésors des Fatimides, où elles avaient même le privilège d'un lieu de garde particulier, les hazāin al-țîb ${ }^{41}$. De manière plus anecdotique, le musc et l'ambre entraient aussi dans la composition de desserts pour le calife, ainsi que dans les sceaux qu'il apposait sur sa correspondance ${ }^{42}$.

Les substances seules sont utilisées mais aussi des composés, dont certains semblent être devenus canoniques. Il en va ainsi du nadd qui est un mélange d'encens, d'ambre et de musc. La gālliya, quant à elle, est un parfum de couleur noire qui est un composé notamment de musc et d'ambre, et qui est utilisé pour les cheveux. Le sukk ${ }^{43}$ désigne la pâte de petites pastilles faites à base d'huile de violette et de musc. Al-Fīrūzābādī le met en rapport avec le rāmik, qui désigne une pâte noire mêlant différentes sortes de musc. Quant à naḍūh et à lahlaha, ils ne semblent pas désigner des mélanges bien définis.

Cependant, cette littérature ancienne cache des réalités dans la variété des produits brûlés que les observateurs modernes ont mises au jour. Ainsi Marceau Gast (1968) distingue au Hoggar, dans les années soixante-dix, parmi les parfums à brûler, des substances utilisées souvent pures comme le benjoin, l'encens et le bdellium, et d'autres destinées à être mélangées. Il énumère le șerghina (Corrigiola telephiifolia), le bois d'agalloche, le mastic, les clous de girofle, le safran, le vrai musc et celui de civette, le nard indien (senbel) et la noix muscade. Mélangées en proportions variées selon les habitudes et le savoir-faire, ces substances entrent toutes dans la composition « d'encens » qui sont brûlés à leur tour sur des braises.

Quant aux fumigations proprement dites, la substance consumée est désignée par le terme de bahūur, qu'il s'agisse de bois ou de résine, au point que ce vocable en vient à signifier "toute substance aromatique », puis «encens » en général. Le terme est entré également en berbère avec le même sens à une époque indéterminée ${ }^{44}$. Le fait de faire brûler une substance pour qu'elle dégage son parfum est le tabhìr ou le tadhìn. Tabhìr a pour acception plus précise de « faire des fumigations », « désinfecter une chambre ». Les formes tabahhara et tadahhana signifient «se parfumer par des fumigations » ${ }^{45}$. L'encensoir ou la cassolette où se consume le combustible est appelé miğmar (ou miğmara ou muğmar), plus rarement midhana, et a évidemment parfois reçu une confection telle qu'il a été considéré comme objet de prix ${ }^{46}$. Le terme de mibhara semble plus récent.

Mais qu'est-ce qui fait qu'une odeur semble bonne ou mauvaise? D'un point de vue physiologique, les médecins ou savants musulmans ${ }^{47}$ ne s'écartent guère des théories de

41. Al-Qaddūmī, Book of gifts and rarities, p. 234 et p. 237. Pour les Abbassides, voir Hilāl al-Ṣābi', Rusūm Dār al-Khiläfah, p. 77-78.

42. Hilāl al-Ṣābi', Rusūm Dār al-Khilāfah, p. 26 et p. 103.

43. Al-Fīrūzābādī, Al-qāmūs al-muhịț, p. 957.

44. GAST 1968, p. 171.

45. BLACHÈre, CHOUÉMI et DeNIZEAU 1967, I. p. 406-407 ; LANE 1863-1893, p. 128-129 et p. 860.

46. Al-Qaddūmī, Book of gifts and rarities, p. 239; al-Fīrūzābādī, Al-qāmūs al-muhīt, p. 393. Dans ce volume: LE MAGUER 2015.

47. CALVERLey et Pollock 2002, I, p. 433-434. 
la physique antique : une odeur est bonne car elle s'accorde au tempérament de celui qui la sent, et elle est putride quand il y a désaccord entre les deux, théorie que l'on retrouve également dans une encyclopédie syriaque du $\mathrm{x}^{\mathrm{e}}$ siècle ${ }^{48}$.

\section{Les usages}

Nous n'aborderons pas l'emploi des parfums dans la cosmétique ou dans les huiles ${ }^{49}$ et onguents destinés au corps, pour nous limiter à leur emploi dans les fumigations. Une fois la résine ou le bois déposé sur les braises ou légèrement enflammé, à quoi peut servir la fumée odorante qui s'en élève dans l'atmosphère en grésillant? Nous distinguerons deux fonctions premières, celle qui concerne l'agrément, que ce soit dans la parfumerie ou le cérémonial, et celle qui a une visée médicale, prophylactique ou thérapeutique.

\section{Parfumerie}

Al-Ǧāhị (m. 255/868), dans le Livre des avares, révèle par l'intermédiaire d'un invité pingre qui se parfumait (tabahhara) grâce à la fumée odorante dispensée chez ses hôtes, que l'encens brûlé était réellement utilisé pour parfumer les vêtements ${ }^{50}$. Par ailleurs, la forme verbale qațara, avec comme nom d'action taqtîir, est formée sur une acception particulière de «qutr » à savoir « morceau de bois d'agalloche » avec le sens de «parfumer ses vêtements avec du bois d'aloès en le brûlant » ${ }^{51}$. Cette acception est ancienne car Abū Ḥanīfa al-Dīnawarī la donne déjà, avec en outre al-miqțara pour désigner l'encensoir à agalloche ${ }^{52}$. On sait qu'al-Ma'mūn pratiquait cet enfumage notamment avec de l'ambre et que cette expérience forcée sur la personne de son vizir Aḥmad b. Abū Hālid fit perdre connaissance à celui-ci ${ }^{53}$. D'ailleurs, le vizir est aussi prié de se présenter parfumé devant le calife, mais sans utiliser une fragrance qui indisposerait son maître ${ }^{54}$.

Il est à remarquer que le Talmud préconisait aussi de faire brûler de l'encens pour imprégner les vêtements d'une odeur agréable ${ }^{55}$. Cette pratique était encore observable au Sahara ${ }^{56}$. Muhammad al-Tamīmī donne par ailleurs plusieurs recettes de teintures parfumées pour les vêtements mais sans mentionner de fumigation; en revanche à propos de divers parfums en grain pour se parfumer l'haleine (al-nakha), il précise qu'ils peuvent

\footnotetext{
48. Job of Edessa, Book of Treasures, p. 161-162.

49. BONNÉRIC 2012, p. 308-309.

50. Al-Ǧāḥiz, Le livre des avares, p. 86-87.

51. LANE 1863-1893, p. 2542-2543.

52. Al-Dīnawarī, The book of plants, p. 220.

53. Al-Fakhrī, Histoire des dynasties musulmanes, p. 393.

54. Hilāl al-Ṣābi', Rusūm Dār al-Khilāfah, p. 30.

55. WIGODER 1993, p. 351.

56. GAST 1968, p. 174.
} 
être également brûlés ${ }^{57}$. Il donne aussi une série de recettes pour la préparation d'huiles à brûler ${ }^{58}$.

\section{Confort d'ambiance et cérémonial}

À l'époque omeyyade, on brûle de l'encens dans des cassolettes près du calife en audience ${ }^{59}$. Par ailleurs des bougies d'ambre installées dans des candélabres d'or sont mentionnées lors du mariage de Hārūn al-Rašīd avec Zubayda en 166/781 ${ }^{60}$. Les lieux de séjour, les salles de banquets, les salons pour les maǧlis sont également parfumés en diverses circonstances réjouissantes ${ }^{61}$. Par une anecdote rapportée par Yahyā ibn Aktam (III ${ }^{\mathrm{e}}$ $\mathrm{IX}^{\mathrm{e}} \mathrm{s}$.), on sait qu'à la fin de repas de travail avec des juristes, il était de coutume d'amener «des cassolettes d'encens pour qu'ils en respirent les arômes et se parfument. ${ }^{62}$ » Ces fumigations font partie des manières de table, comme se laver les mains, à la fin du repas ${ }^{63}$.

Sans que cela fasse partie du protocole, il semble que l'audience des dignitaires étrangers était accompagnée par des fumigations odorantes, comme lors de l'audience accordée par Șamșām al-Dawla, en 376/986, à un dignitaire byzantin réfugié en territoire musulman et libéré à cette occasion. Lors de l'audience, des brasiers en or reçoivent des parfums à brûler ${ }^{64}$. De son séjour forcé à Constantinople, Hārūn b Yahyā (fin III $/ \mathrm{IX}^{\mathrm{e}} \mathrm{s}$.) a retenu l'usage des cassolettes (mağāmir) d'encens dans le cortège impérial ${ }^{65}$, ce qui laisse à penser que les témoignages sur les usages étrangers pouvaient influencer l'usage local.

Nasir-i Husraw (m.av.471/1078) remarque dans le cortège du calife fatimide des porteurs de cassolettes de parfums dans lesquelles on fait brûler de l'ambre ('anbar) et du bois d'agalloche ('ūd) ${ }^{66}$. Al-Maqrīzī (m. 845/1442) apporte plus de détails, signalant que les porteurs de cassolettes étaient trois de chaque côté du calife et gardaient tous du charbon dans leurs manches afin d'alimenter l'encensoir. Un autre fonctionnaire les accompagnait, portant une boîte avec l'encens qu'il plaçait sur les braises ${ }^{67}$.

\footnotetext{
57. Al-Tamīmī, Kitāb Habīb al-'arūs wa-rayhān al-nufūs, p. 108.

58. Al-Tamīmī, Kitāb Habīb al-'arūs wa-rayhān al-nufūs, p. 19, 25, 96, 125, 159, 165, 179 et 217.

59. SAUVAGET 1947, p. 131, à partir du Kitāb al-ä̇ānī, I, p. 26 et V, p. 166.

60. Al-Qaddūmī, Book of gifts and rarities, p. 121.

61. Al-Qaddūmī, Book of gifts and rarities, p. 119 et p. 132.

62. Al-Mas' 'ùdī, Les prairies d'or, IV, p. 1113.

63. AHSAN 1979, p. 162.

64. Hilāl al-Șābi', Rusūm Dār al-Khilāfah, p. 20.

65. Ibn Rustih, A'Tāq al-nafìsa, p. 124.

66. Nasir-i Khusraw, Sefer nameh, p. 48 et trad. p. 141.

67. Al-Maqrīzī, Al-mawāì iz, II, p. 289 ; CANARD 1951, p. 384-385.
} 
Les Milles et une nuits fournissent aussi de nombreuses évocations de l'usage des parfums fumant après un repas, avant d'entamer une conversation ou pour agrémenter une rencontre, cette entrée en littérature d'une scène de la vie courante prouve la diffusion de l'acte, ainsi par exemple dans cet épisode du conte du troisième qalandar :

J'ouvris la porte plaquée d'or et j'entrai. Et voilà que j'étais confronté à un parfum que j'humais [...]. Je pénétrai dans une resserre et je trouvai du safran étendu sur le sol, des bougies parfumées, des lampes (qanādīl) en or et en argent où brûlaient des huiles précieuses. Les bougies étaient brochées avec des morceaux d'agalloche et d'ambre. Je voyais deux grands brûle-parfums (mibhatayn) - chacun de la taille d'une terrine - remplis de braises incandescentes. Elles étaient pleines de nadd et d'encens. Je m'imprégnai de cet encens, de ces fumées de bougies, de musc et de safran. ${ }^{68}$

\section{Usage médical prophylactique : purifier l'air}

Ibn Riḍān (m.453/1061) recommande, si l'air est chaud, l'usage de parfums et de fumigations dans les pièces, en mentionnant le bois de santal. Si l'air est froid, il faut le parfumer avec du nadd (composé d'encens, ambre et musc), de l'ambre, du bois d'agalloche, des épices, de l'encens, etc. Si l'air est sec, il faut faire des fumigations avec $\mathrm{du}$ bois d'agalloche, du nadd, de l'ambre, de l'encens, du styrax et de la sandaraque. Si l'air est putride et sec, il faut faire brûler du tamaris ou de l'encens, entre autres ${ }^{69}$. Pour son contemporain Ibn Buṭlān (m. 458/1066), des fumigations d'encens sont aussi utiles pour purifier l'air des mauvaises odeurs ainsi que dans les cas où la variole et la peste se multiplient ${ }^{70}$. On doit également faire avaler de l'encens mastiqué à quelqu'un qui a été mordu par un scorpion.

Le médecin Ibn Ǧumay (m. 594/1198), qui s’intéresse en particulier à l'environnement d'Alexandrie, donne plusieurs conseils pour y choisir son habitation par rapport aux vents et pour y assainir l'atmosphère :

Il convient que l'on choisisse parmi les maisons [d'Alexandrie] pour y habiter celle dont les portes des pièces et des salons sont ouvertes, orientées vers l'est et le nord, mais fermées à l'ouest et au sud. Elle aura des ouvertures par lesquelles passera l'air qui y entrera afin que ces courants d'air la traversent et que les rayons du soleil y entrent. Ce qui a été rassemblé comme miasme à l'intérieur de la maison sera dispersé et décomposé. (...) La demeure doit être éloignée notamment des cimetières, des jardins potagers (al-mabāqil), des tas de fumiers, des tanneries, des lieux de fabrication d'amidon, de mauvaises odeurs et des foyers des bains. En effet, tout cela vicie l'air en y mélangeant ses vapeurs nocives et ses fumées. Il convient ensuite de le nettoyer de ses miasmes, de ses particules délétères et de ses saletés qui sont dans la plupart des habitations et que l'on considère comme méprisables. Elles sont en effet

68. The thousand and one nights, I, p. 198, v.a. p. 116, 122, 140, 341, 382, 523.

69. DOLS et GAMAL 1984, p. 132.

70. Ibn Buțān, Taqwîm al-șihhhâ, p. xxxviii, 262, 15 ; XL, 279, 15 et 280, 15. D’autres emplois sont préconisés : on le rencontre sous forme de sirop bénéfique pour ceux qui souffrent de la variole, d'érysipèle, d'érythème et de maladies semblables. 
toutes nocives pour l'air. Ainsi, quand il fait froid, on alimente un certain nombre de feux avec, par exemple, du charbon de chêne d'Alep (al-ballūt ), du bois de genèvrier (al-'ar'ar), du laurier (al-ġār), du genévrier sabine (al-abhul), du lotus (al-sidr), du tamaris (al-atal), du cyprès (al-sarw), de l'aunée (al-šābānk), du tamaris (al-țarfä', Tamaris gallica) et du centinode (al-quḍ̂āab). On brûle aussi des racines de safran (baland), du musc, de l'ambre, de l'agalloche brut (al-'úd al-hăàm), du safran ${ }^{71}$, du sad (?) élevé, de la giroflée, de la sandaraque (sandarūs), du ciste (ou ladanum, al-lādan), du storax (al-may'a), du mastic (al-maștaka), de la résine de térébinthe ('ilkal-buțm), du costus doux (al-qust al-halw), des blattes de Byzance (azfär al-țïb), du souchet odorant (al-su'd) ${ }^{72}$, de la citronelle (al-idhur), de la fagara (al-fägira). On fait sécher les plantes odoriférantes, les feuilles des arbres et leurs extrémités comme le narcisse (al-narğīs), la rose musquée (nasrīn), le jasmin, la giroflée jaune (al-hìirì), l'ochna (al-faranğumušk), des fleurs odorantes de basilic (al-rayhān al-hamāhim), de menthe (al-namām), de mazarbahūšs (?), de bigaradier (al-naranğ), de cedrat (al-atruğ), de citron (al-laymūn) ainsi que ses feuilles et les extrémités de ses branches. [On peut ajouter] les bouts du rosier de Jéricho (šağarat Maryam) et de l'aurone (al-šĭh). Durant les périodes de fortes chaleurs, on brûlera et on fera des fumigations de rose (ward), de myrte (al-ās), de pastilles odoriférantes (al-sukk) et d'autres parfums, ainsi que d'écorces de grenades, de cognassiers (al-safarğal), de pommes séchées, de sciure de sā’im (?), de teck (al-säğ), d'ébène et de santal. On arrose cela avec du vinaigre et on en renifle souvent avec de l'eau de rose. ${ }^{73}$

Cet usage prophylactique des fumées est évident chez al-Šaqūrī car, dans sa Maqāla fìl-awbi'a, écrite lors de la peste de 1348, il préconise l'usage de fumigations pour purifier l'air ${ }^{74}$. Il faut assainir l'atmosphère, écrit-il, d'abord par des fumigations de fumées médicamenteuses : goudron ( qitrān), vernis (sandarās), encens (kundur), styrax (may'a) et myrrhe (murr), quand le temps est nuageux et brumeux. Les autres fumigations sont celles des parfums : essence de rose (ward), bois de santal (sandalān), tamaris (zaraf), camphre ( $k \bar{a} f \bar{u} r$ ) et bois d'agalloche ('ūd).

Le camphre est souvent utilisé pour la purification et la désinfection de l'air. Ibn al-Wardī, qui meurt de la peste à Alep en 1349, rapporte que les habitants de la ville cherchaient protection avec de l'ambre, du camphre, du bois de cyprès et du bois de santal 75 .

On tente certes de purifier l'air ambiant par des fumées, mais la pratique est préconisée aussi pour des récipients. Ibn Rị̣wān recommande ainsi des fumigations de mastic en sorte de purifier les récipients prévus pour l'eau ${ }^{76}$. Et les manuels de hisba enregistrent également la recommandation de faire brûler de l'encens dans les bains après les avoir nettoyés et avant que les premiers clients n'arrivent ${ }^{77}$. Cette idée n'était pas neuve car

71. On peut remarquer que si le terme arabe remonte à l'akkadien azupirānū, les Babyloniens l'utilisaient déjà en fumigation à des fins médicales, voir al-Kindī, Medical Formulary, p. 275-276.

72. Celui-ci était déjà employé en fumigation en médecine babylonienne, voir al-Kindī, Medical Formulary, p. 282.

73. Ibn Ǧumay', Risāla fì țibb al-Iskandariyya, p. 376-377.

74. Al-Šaqūrī, Maqāla fì l-awbi'a, p. 62-63.

75. Ibn al-Wardī, Risāla al-Naba' 'an al-Waba', p. 443-455.

76. DOLS et GAMAL 1984, p. 38.

77. BEHRNAUER 1861, p. 39. 
Ibn Sayyār al-Warrāq (IV $/ \mathrm{X}^{\mathrm{e}} \mathrm{s}$.) dans son livre de cuisine conseille des fumigations d'agalloche ( $(\bar{u} d)$ dans les contenants, les pots et les jarres pour en chasser les mauvaises odeurs ${ }^{78}$.

\section{Usage thérapeutique (aromathérapie)}

Si les fumées odorantes sont supposées assainir l'atmosphère ambiante, elles peuvent parfois intervenir comme médicaments mais cet usage est plus restreint, souvent cantonné aux affections supposées du nez ${ }^{79}$ et des voies respiratoires où leur administration se fait par inhalation ou fumigation. Une même substance peut être utilisée de différentes manières. Ainsi, l'encens est utilisé sous deux formes : en fumigation, par exemple dans le cas d'un rhume, et comme partie de médicament composé ${ }^{80}$. Ibn Halṣūn au XIII siècle, en Andalus, cite une série de substances aromatiques opératoires, comme les épices et les huiles, mais sans en préciser l'usage ${ }^{81}$. Ses confrères ont cependant des avis très divers sur la matière. Yuhannā ibn Masawayh ne mentionne que les fumigations de blattes de Byzance (al-azfār) et celle du ladanum (al-lādan) ${ }^{82}$. Et selon le médecin persan Muwaffaq, qui écrit au plus tard en 377/987 un traité pour l'émir samanide Manșūr ibn Nūh, « la fumée de l'ambre jaune, de l'encens et de l'aloès dilue l'air dense et nous défend de l'air cholérique. Elle renforce aussi le cerveau et le cœur. ${ }^{83}$ » Nağìb al-Dīn al-Samarqandī (VII $/ \mathrm{XIII}^{\mathrm{e}} \mathrm{s}$. ) mentionne les fumigations d'encens comme remèdes aux rhumes de cerveau sans fièvre, précisant qu'il existe aussi des collyres d'encens qui cicatrisent les plaies et font mûrir les abcès ${ }^{84}$. Sa poussière, avec d'autres substances, insufflée dans le nez, arrête aussi le saignement. Cependant, il consacre un chapitre particulier aux « inhalations, sternutatoires et fumigations » (Fīl-sa' ūțāt wa-l-'ațūsāt wa-l-bahurāt) où il cite une série de fumigations à pratiquer pour diverses maladies soit à partir de préparations liquides alors chauffées ou jetées sur des pierres chaudes, soit comme des fumées proprement dites quand ce sont des résines qui sont brûlées. Dans le premier cas, nous pourrions mieux parler d'inhalations. En dehors des voies supérieures, Barhebraeus recommande l'utilisation des azfār al-țīb, avec de l'encens en fumigations, notamment pour l'atrésie de l'utérus ${ }^{85}$.

Ibn al-Bayțār enregistre ainsi l'emploi en fumigation du styrax (may'a), du bois de santal dont les propriétés aromatiques sont prisées ${ }^{86}$ et enfin du bois d'agalloche (' $\bar{u} d$ )

78. Ibn Sayyār al-Warrāq, Annals of the caliphs' kitchens, p. 662, 676 et 775.

79. LEVEY 1973, p. 88-90.

80. Syrian Anatomy, Pathology and Therapeutics, II, p. 72 et p. 215 et passim.

81. Ibn Hुalṣūn, Kitāb al-ag̉diya, p. 123-124.

82. Ibn Masawayh, Kitāb ğawāhir al-țīb al-mufrada, p. 22 et 23.

83. LEWICKI 1984, p. 125.

84. Al-Samarqandī, al-Aqrābādīn 'alā tartīb al-asbāb, p. 13, 19, 23, 37 ; al-Samarqandī, The medical formulary, p. 157-162 ; LEVEY 1973, p. 88, pour les fumigations.

85. Barhebraeus, The abgridged version of the « Book of simple drugs », I, p. 224-228.

86. Ibn al-Bayțār, Traité des simples, II, p. 350-352, p. 383-384 et p. 484-485. 
qui ferait descendre la pituite du cerveau. La fumée de sandaraque (sandarūs) ${ }^{87}$ serait, elle, utile contre les hémorroïdes, le coryza et les humidités de la tête. De manière incidente, Ibn al-Bayțāar ${ }^{88}$ évoque aussi l'usage d'un résidu de la combustion, la suie (duhāan), dont celle d'encens, de myrrhe, de styrax est employée notamment dans les maladies des yeux.

Les fumées odorantes sont censées guérir, mais $\mathrm{Ibn}$ Wahšiya $\left(\mathrm{VI}^{\mathrm{e}} / \mathrm{X}^{\mathrm{e}} \mathrm{s}\right.$.) considère également les odeurs comme capables de faire mourir ${ }^{89}$. Et l'auteur de préciser les odeurs mortelles que l'on peut cacher par un parfum agréable, puis différents poisons qui font lentement leur effet après avoir été simplement sentis, inhalés ou reniflés. Si certains bois donnent une bonne odeur en brûlant, il en mentionne d'autres qui, jetés au feu, produisent une fumée fatale.

Les fumeroles parfumées ont ainsi été conçues comme ayant une action sur les hommes et les choses, mais pouvaient-elles avoir une influence sur le monde spirituel? Il semble bien que, lentement, la fumée se soit immiscée dans certaines formes de dévotion.

\section{Usage religieux}

On ne constate pas d'islamisation de l'encens, comme on peut parler de sa christianisation, bien que nous possédions des mentions éparses d'utilisation de fumigations dans des mosquées particulières. Ibn Rustih (début $\mathrm{IV}^{\mathrm{e}} / \mathrm{X}^{\mathrm{e}} \mathrm{s}$.) renseigne ainsi l'usage d'un encensoir rapporté de Syrie, dans la mosquée de Médine sous 'Umar b. al-Huatțāb (m. 23/644) ${ }^{90}$. L'encensoir était décoré par des figures en argent. La mosquée était ainsi encensée lors des prières et durant le ramadān. Selon Ibn Rustih, cette pratique était encore en vigueur quand il écrivait, au début du Xe siècle. Al-Samhūdī (m. 891/1506) confirme largement cette pratique de la fumigation (iğmār) de la mosquée de Médine à l'instigation du prophète, puis en particulier sous 'Umar la nuit et le jour du vendredi, ainsi que durant le ramadān ${ }^{91}$. Sous le règne de 'Umar, elle était faite à partir d'écorce d'agalloche (safat min 'ùd, litt. « écaille » d'agalloche) et c'était le minbar qui était parfumé. Il est à remarquer qu'il ne ressort pas des textes que ce soit pour honorer, "encenser » l'endroit, mais plus pour parfumer l'atmosphère où les musulmans se rassemblaient. En ce sens, cette fumigation est à distinguer de l'onction du mihrab. Se défier cependant de toute généralisation hâtive : cet usage ne semble pas s'être diffusé. Pour Médine, ni Nașīr-i Husraw, ni Ibn Ğubayr (m. 614/1217), ni Ibn Bațtūța (m. 770/1368-9 ou 779/1377) n'en parlent. Pour La Mecque, Ibn al-Faqīh a conservé la tradition selon laquelle Mu'āwiya aurait été le premier à parfumer (țayyaba) la Kába avec des onguents (halūq) et des encens (miğmar) ${ }^{92}$. À Jérusalem, sous 'Abd al-Malik (m. 86/705) et al-Walīd (m. 96/715), le

\footnotetext{
87. Ibn al-Bayțār, Traité des simples, II, p. 297-298.

88. Ibn al-Bayțār, Traité des simples, II, p. 82.

89. Ibn Waḥ̌iyya, Medieval Arabic Toxicology, p. 39-45.

90. Ibn Rustih, A' Tāq al-nafìsa, p. 66.

91. Al-Samhūdī, Wafä' al-wafa, II, p. 449-450.

92. Ibn al-Faqīh, Muhtașar kitāb al-buldān, p. 20.
} 
rocher recevait une onction et était parfumé par des fumigations ${ }^{93}$. D'un point de vue plus général, nous pouvons souligner que l'islam n'a pas d'acte rituel qui pourrait être accompagné ou renforcé de manière symbolique par une fumée odorante. Aucun texte n'associe expressément une fumigation avec un acte cultuel. Al-Maqrīzī a bien conservé le souvenir de l'encensement de mosquées à l'époque fatimide mais ces fumigations avaient lieu lors de la visite du calife et honoraient d'abord sa personne ${ }^{94}$. Les encensoirs étaient au nombre de quatre, l'un était installé dans le mihrāab, deux autres de chaque côté du minbar et le quatrième à l'endroit où se tenait le calife. Les notions d'offrande et de consécration sont absentes, contrairement au christianisme. Dans l'Église tardo-antique ${ }^{95}$, on se sert de l'encensoir en diverses occasions. Il est utilisé pour amener de bonnes odeurs lors des réunions, on encense aussi de manière honorifique des objets ou des personnes par vénération. Plus proche d'une fonction magique, il est utilisé lors d'exorcismes pour chasser les mauvais esprits et inversement l'encens qui brûle est conçu comme offrande. Si l'origine de cette pratique n'est pas établie avec exactitude, on sait que dans l'Église orientale, l'usage de l'encens est attesté à la fin du IV siècle par le Testament de saint Ephrem. Il apparaît qu'il n'avait pas de fonction religieuse mais visait à donner simplement une bonne odeur à l'église avant la messe. À la fin du V siècle, cependant, l'encensement se généralise au commencement de la messe en Syrie, et c'est une pratique attestée en Égypte au IX ${ }^{\mathrm{e}}$ siècle. Mais les Coptes faisaient une distinction, sans doute avant tout de principe, entre les substances qui avaient été utilisées par les païens, comme le lubān et le styrax, et celles qu'ils pouvaient employer. De même, l'ambre, qui est issu d'un animal marin, ne pouvait pas être utilisé lors de l'encensement. Il est à remarquer que faire brûler de l'encens, hors église, est attesté dans le culte des saints au $\mathrm{V}^{\mathrm{e}}$ siècle.

Quant au judaïsme, on sait que la synagogue était enfumée, mais après le shabbat puisqu'on ne peut pas allumer un feu ce jour-là, pour désodoriser la pièce ${ }^{96}$. Dans le contexte domestique, cela se pratiquait après les repas. On disait une bénédiction sur le muğmar ou brasier. Trois types de brûle-parfums sont ainsi recensés dans la documentation de la Genizah.

Cependant, en islam, l'encens est réintroduit officiellement par le soufisme. Chez les soufis, le terme de bahūr semble être le nom utilisé généralement pour ces résines brûlées pour parfumer les lieux de culte. Mais les textes montrent qu'il s'agissait d'une pratique qui concernait l'ensemble des fondations pieuses notamment au moment de fêtes religieuses

93. Muğīr al-Dīn, Histoire de Jérusalem, p. 52-53. L'information n'est pas sans poser de problème car on y fait mention textuellement de 'ūd qimārī soit du bois d'agalloche (ou d'aloès par approximation) khmer ; or, si la nisba qimārī associée au bois d'agalloche est courante et normale aux $\mathrm{IX}^{\mathrm{e}}$ et $\mathrm{X}^{\mathrm{e}}$ siècle, dans le premier quart du viII ${ }^{\mathrm{e}}$ siècle elle est très problématique car le royaume khmer n'existe pas encore. Il n'y a aucune raison qu'un produit exporté alors d'Asie ait porté ce qualificatif. Il nous paraît pour cette raison que l'information rapportée par Muğīr al-Dīn a été interpolée dans le détail.

94. Al-Maqrīzī, Al-mawāìz, II, p. 389, notamment dans les mosquées d'al-Azhar et d'al-Ḥākim.

95. FERHENBACH 1922 ; ASHBROOK HARVEY 2006, p. 75-83.

96. GOITEIN 1983, p. 137-138. 
ou de certaines occasions. Les bahūū sont même cités dans les charges couvertes par un waqf ${ }^{97}$. Les fumigations ont lieu lors des séances de $\underline{d i k r}{ }^{98}$. Le bahūur est brûlé par le murīd durant les litanies ou les prières. Il faciliterait le contact avec le monde spirituel, accélérant l'arrivée des prières. Il rendrait heureux les anges et les esprits. Par extension, il chasse les mauvais esprits ${ }^{99}$. Il n'y a pas lieu ici de détailler l'usage de l'encens dans la magie ${ }^{100}$, mais il n'y a guère de doute que les actes posés avec ces fumeroles odorantes avaient le même sens dans l'esprit de l'exécuteur. Pour la période médiévale, rappelons simplement que Ğamal al-Dīn al-Idrīsī (m. 649/1251) rapporte que les candidats à un poste auprès du sultan mamelouk allaient encenser le sphinx ${ }^{101}$.

Ces multiples propriétés attribuées à l'encens à la limite de la magie et dans un contexte de syncrétisme n'apparaissent que subrepticement dans les sources écrites, et souvent pour être condamnées. Ainsi, Ibn Taymiyya (m. 728/1328) dénonce et juge malsaines ces pratiques à l'époque mamelouke :

Les gens du commun s'imaginent que l'encens magique est profitable, par sa bénédiction, contre le mauvais œil, la sorcellerie, les maladies et la vermine. [...] Une grande foule de gens sort le jeudi qui précède ce jeudi-là, pour encenser les tombes ; ils appellent ce dernier jour, le Grand Jeudi (c'est-à-dire le Jeudi saint). [...] Les fêtes des infidèles sont nombreuses et diverses ; parmi elles, il y a ce misérable jeudi qui est à la fin de leur jeûne [...], tout ce que les gens commettent durant cette semaine (la semaine sainte) est répréhensible, comme : la sortie des femmes, l'encensement des tombes, l'exposition des vêtements sur la terrasse ; le fait d'écrire sur des feuilles et de les coller aux portes; l'adoption de ces fêtes comme dates fixes pour vendre de l'encens ; de même, l'achat d'encens à cette époque, si elle est choisie comme date de vente ; l'emploi magique de l'encens en général, à ce moment-là ou à un autre, ou l'intention d'acheter de l'encens magique ; car l'usage magique de l'encens et le fait de le choisir comme offrande, fait partie de la religion des chrétiens et des Sabéens; l'encens n'est qu'un parfum, avec la vapeur duquel on se parfume, de même que l'on se parfume avec les autres parfums, comme le musc et d'autres, qui ont des parties vaporeuses, même si elles sont subtiles, ou qui ont une odeur pure ; et l'on aime se servir d'encens, comme on aime se parfumer. ${ }^{102}$

Dans une société composée de plusieurs communautés religieuses dont certaines pratiques cultuelles étaient visibles publiquement, il était inévitable que les tenants du discours majoritairement autoritatif - en l'espèce musulman - condamnent ces mélanges d'influences. Elles étaient conçues comme des atteintes à l'orthopraxie.

\footnotetext{
97. ASALI 1983, p. 116.

98. BOUBAKEUR 2003, p. 464. L'auteur parle de benjoin.

99. CHEBEL 1995, p. 179.

100. Dans ce volume : CoUlON 2015.

101. Al-Idrīsī, Anwār 'ulwī al-ağrām, p. 151.

102. TROUPEAU 1979, p. 798 et 800 ; MEMON 1976, p. 221.
} 


\section{Conclusion}

Réalité volatile s'il en est, les fumigations odorantes étaient bien des actes courants dans la culture arabo-musulmane médiévale. Si les attestations littéraires restent éparses, les arts du métal ${ }^{103}$ nous ont conservé un certain nombre de brûle-parfums de plusieurs types et de toutes les époques qui montrent que brûler une résine, du bois odoriférant, des aromates ou un composé huileux était un acte commun. Geste et moment dans le savoir-vivre princier, la fumée odorante semble se répandre naturellement dans la sociabilité des notables ou, en tout cas, de ceux qui ont les moyens de s'acheter ces produits pour la plupart exotiques. Ces petits braseros parfument l'atmosphère, les vêtements et les cheveux de ceux qui s'en approchent. Si la médecine fait grand cas de ces fumeroles censées purifier l'air et envelopper le corps pour le pénétrer par ses orifices, la sphère religieuse semble prendre du temps pour récupérer le geste, encore manifestement marqué par la mémoire de rites païens et en tout cas observable par tous dans le culte chrétien. La mosquée de Médine a connu pendant un temps cette pratique, mais elle ne semble pas s'être perpétuée. C'est la piété populaire qui réintroduit la fumée dans la dévotion, d'une manière ouvertement acceptée avec le culte des saints locaux, mais mi-clandestine dans la magie, ce dont les esprits sévères se choquent. Passant de l'état solide et liquide à celui de l'air par l'action du feu, d'une manière symbolique, les substances odorantes libéraient leurs fragrances en transitant par les quatre états de la matière selon la physique du temps. Le mouvement finalement ascensionnel de la fumée lui permettait de se dissiper au-delà du regard des hommes.

\section{Bibliographie}

\section{Sources}

Barhebraeus, The abgridged version of the "Book of simple drugs" of Ahmad ibn Muhammad al-Ghâfiqî by Gregorius Abu'l-Farag (Barhebraeus), éd. et trad. Max MEYERHOF et George P. SOBHY BEY, Le Caire, The Egyptian University, 4 vol, 1932-1940.

Al-Bīrūnī, Kitāb al-șaydana fì l-țibb, éd. 'Abbas ZARYAB, Téhéran, Markaz-i našr-i Dānišgāhī, 1991.

Book of gifts and rarities. Kitāb al-hadāyā wa-l-tuhaf, trad. Ghāda al Hijjāwī AL-QADDŪMĪ, Cambridge (Massachusetts), Harvard University Press (Harvard Middle Eastern Monographs 29), 1996.

Al-Buhārī, Les traditions islamiques, trad. Octave HoudAs et William MARÇAIS, Paris, Librairie d'Amérique et d'Orient, 1984, 4 vol.

Al-Dimašqī, Abū l-Faḍl Ğa far b. 'Alī, Kitāb al-išāra ilā maḥāsin al-tiǧāra, éd. Maḥmūd AL-ARNĀ'ūT, Beyrouth, Dār Șādir, 1999.

103. ATIL, CHASE et JeTT 1985, p. 58-59 (brûle-parfum égyptien, VIII ${ }^{\mathrm{e}}-\mathrm{IX}^{\mathrm{e}}$ s.), p. $92-93$ (brûle-parfum seldjouke, Iran, $\mathrm{XII}^{\mathrm{e}}$-XIII ${ }^{\mathrm{e}}$ s.), p. 171-175 (globe mamelouke, Égypte XIII ${ }^{\mathrm{e}}$ s.). Dans ce volume : LE MAGUER 2015. 
Al-Dīnawarī, Abū Ḥanīfa, The book of plants. Part of the monograph section, éd. Bernhard LEWIN, Wiesbaden, Otto Harrassowitz, 1974.

Al-Fakhrī, Ibn al-Ṭiqțaqā, Histoire des dynasties musulmanes, trad. Émile AMAR, Paris, Ernest Leroux, 1910.

Al-Fīrūzābādī, al-Qāmūs al-muhịț, Beyrouth, Dār al-kutub al-ilmiyya, 2013.

Al-Ǧāhịiz, Le livre des avares, trad. Charles PELLAT, Paris, Maisonneuve et Larose, 1997.

Al-Ǧāhịiz, « Ǧāhiiziana, I. Le Kitāb al-tabașșur bi-l-tiǧāra attribué à Ǧāhiz », trad. Charles PELLAT, Arabica I, 1954, p. 153-165.

Al-Ǧazīrī, 'Abd al-Raḥmān, Kitāb al-figh 'alā al-madāhib al-arba'a, Le Caire, s.n., 1986, 5 vol.

Hilāl al-Ṣābi', Rusūm dār al-hilāfa, trad. Elie A. SALEM , Beyrouth, Lebanese commission for the translation of great works, 1977.

Ibn Abī Ușaybi'a, 'Uyūn al-anbā' fì țabaqāt al-ațibbā', Beyrouth, s.d.

Ibn al-Bayțār, Traité des simples, trad. Lucien LECLERC, Paris, Imprimerie nationale (Notices et extraits des manuscrits de la bibliothèque nationale 23-26), 1877-1883.

Ibn Buțlān, Le Taqwîm al-șihhâa (Tacuini Sanitatis) d'Ibn Butlân: un traité médical du XI siècle, éd. et trad. Hossam ElKHADEM, Louvain, Peeters, 1990.

Ibn al-Faqīh, Muhtașar kitāb al-buldān, éd. Michael Jan DE GOEJE, Leyde, E.J. Brill, 1885.

Ibn Ǧumay', Hibatallāh b. Zayn b. Hasan, Risāla fì țibb al-Iskandariyya, in Ibn Ǧumay’, Hibatallāh ibn Zayn ibn Hasan, Medical Treatise/Rasā'il fī l-Ṭibb, éd. facisimile Fuat SEZGIN et Fabian Käs, Frankfurt am Main, Institut für Geschichte der Arabisch-Islamischen Wissenschaften, 2010.

Ibn Ḩalṣūn, Kitāb al-ag̣diya, éd. Suzanne GIGANDET, Damas, Ifead, 1996.

Ibn Manẓūr, Lisān al-'Arab, Beyrouth, Dār ihyyā’ al-turāt al-'arabī, 1997, 18 vol.

Ibn Masawayh, «Kitâb jawâhir al-tib al-mufrada. Traité sur les substances simples aromatiques par Yohanna ben Massawaih » éd. Paul SBATH, Bulletin de l'Institut d'Égypte 26, 1937, p. 5-27.

Ibn al-Qifțī, Tārīh al-ḥukamāa', éd. Julius LIPPERT, Leipzig, Dieterich'sche Verlagsbuchandlung, 1903.

Ibn Rustih, al-A lāq al-nafisa, éd. Michael Jan DE GoEJE, Leyde, E.J. Brill, 1892.

Ibn Sayyār al-Warrāq, Annals of the caliphs' kitchens. Ibn Sayyâr al-Warrâq's Tenth-Century Baghdadi Cookbook, trad. Nawal NASRALLAH, Leyde, E.J. Brill, 2010.

Ibn Wahšiyya, Medieval Arabic Toxicology: The Book on Poisons of ibn Wahshiya, tr. Martin LEVEY, Philadelphia, The American Philosophical Society, 1966a.

Ibn al-Wardī, Risāla al-Naba' 'an al-Waba', tr. Michael DoLs, « Ibn al-Wardī's Risāla al-Naba' 'an al-Waba': a translation of a major source for the history of the Black Death in the Near East ", in Dickran K. KOUYMJIAN (éd.), Near Eastern Numismatics, Iconography and History: Studies in honor of George C. Miles, Beyrouth, American University Press, 1974, p. 443-455.

Al-Idrīsī, Kitāb al-ğāmi li-șifāt aštāt al-nabāt wa-ḍun̄o anwāe al-mufradāt, éd. facisimile Fuat SEZGIN, Frankfurt am Main, Institut für Geschichte der Arabisch-Islamischen Wissenschaften, 1995.

Al-Idrīsī, Abū Ǧa 'far, Anwār 'ulwī al-ağrām fì l-kašf 'an asrār al-ahrām, éd. Ulrich HAARMANN, Beyrouth, Franz Steiner Verlag, 1991.

Job of Edessa, Book of Treasures, éd. et trad. Alphonse MinGANA, Cambridge, W. Heffer 1935.

Al-Kindī, Ya qūb b. Isḥāq, Kitāb kìmiyā’ al- 'ițr wa-l-tașî̀dāt, éd. Karl GARBERS, Leipzig (Abhandlungen für die Kunde des Morgenlandes 30), 1948. 
Al-Kindī, Ya 'qūb b. Isḥāq, The Medical Formulary or Aqrābādhīn of al-Kindī, éd. et tr. Martin LEVEY, Milwaukee, University of Wisconsin Press, 1966.

The thousand and one nights (Alf layla wa-layla). From the earliest known sources, éd. Mouhsin MAHDI Leyde, E.J. Brill, 2011.

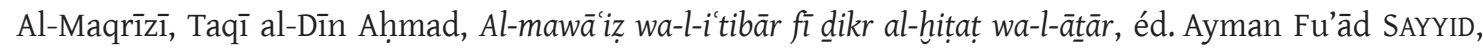
Londres, Al-Furqān Islamic Heritage Foundation, 2002, vol. 2.

Al-Mas 'ùdī, Les prairies d'or, trad. Charles Pellat, Paris, Société asiatique, 1962-1989.

Muğīir al-Dīn, Histoire de Jérusalem et d'Hébron depuis Abraham jusqu'à la fin du Xve siècle de Jésus Christ. Fragments de la Chronique de Moudjir-ed-Dyn, trad. Henry SAUVAIRE, Paris, Ernest Leroux, 1876.

Nasir-i Khusraw, Sefer nameh, éd. et trad. Charles SCHEFER, Paris, Ernest Leroux, 1881.

Al-Nawāwī, Abū Zakariyyā Yahyāa b. Šaraf, Minhāğ al-țālibīn, éd. Lodewijk Willem C. VAN DEN BERG, Batavia, Imprimerie du gouvernement, 1882.

Al-Nuwayrī, Aḥmad b. 'Abd al-Wahhāb, Nihāyat al-arab fífunūn al-adab, éd. Mufīd QAMAYHA, Beyrouth, Dār al-kutub al-îlmiyya, vol. 12, 2004.

Al-Qazwînî, El Libro de las plantas, trad. Ingrid BejARANo EsCANILLA et Ana María CABO GonZÁLEZ, Séville, Universitad de Sevilla, 2011.

Reinaud, Joseph Toussaint, Relation des voyages faits par les Arabes et les Persans dans l'Inde et la Chine, Paris, Imprimerie nationale, 1811.

Al-Samarqandī, The medical formulary of al-Samarqandī, trad. Martin LEVEY and Noury AL-KHALEDY, Philadelphie, University of Pennsylvania Press, 1967.

Al-Samarqandī, Nağīb al-Dīn, al-Aqrābādīn 'alā tartīb al-asbāb, éd. Georges ToHMÉ, Beyrouth, Maktabat Lubnān, 1994.

Al-Samhūdī, 'Alī b. 'Abd Allāh, Wafā' al-wafā bi-ahbā̄r dār al-mușțafā, éd. Qāsim AL-SĀMARRĀ'Ī, Londres, Al-Furqān Islamic Heritage Foundation, 2001, 5 vol.

Al-Šaqūrī, Maqāla fìl-awbi'a, «Al-Shaquri, Maqâla fī l-awbi'a. Un opuscule grenadin sur la peste noire de 1348, la nasîba de Muhammad al-Shaqûrî̀, trad. Rachel ARIÉ, in Rachel ARIÉ, Études sur la civilisation de l'Espagne musulmane, Leyde, E.J. Brill, 1990, p. 57-67.

Al-Sīrāfī, Mūsā b. Rabāḥ al-Awsī, Al-ṣaḥịh min aḩbār al-biḥār wa-'ağāibi-hā, éd. Yūsuf AL-HĀDĪ, Damas, Dār al-iqrā', 2006.

Al-Suyūṭ̂̄, Al-Maqāma al-miskiyya, «Four perfumes of Arabia: a translation of al-Suyūțī's al-maqāma al-miskiyya », trad. Geert Jan van GELDER, Res orientales XI, dossier thématique : Parfums d'Orient, Ryka GYSELEN (éd.), 1998, p. 189-202.

Syrian Anatomy, Pathology and Therapeutics or Book of Medecine, éd. et trad. Willis BUDGE, Londres, Oxford University Press, 1913.

Al-Tamīmī, Muhammad b. Ahmad b. Saīd , Kitāb Habīb al-'arūs wa-rayhān al-nufūs / On Perfumes, éd. facsimile Fuat SEZGIN, Frankfurt am Main, Institut für Geschichte der Arabisch-Islamischen Wissenschaften, 2011.

\section{Études}

AHSAN Muhammad Manazir 1979, Social life under the Abbasids, Londres, Longman.

AKASOY Anna et YoELI-TLALIN Romit 2007, «Along the musk routes. Exchanges between Tibet and the Islamic world », Asian medicine 3, p. 217-240. 
ASALI Kamil J. 1985, Jerusalem historical documents, II, Amman, Mu'assadat āl al-bayt.

ATIL Esin, CHASE William Thomas et JETT Paul 1985, Islamic metalwork in the Freer gallery of art, Washington D.C., The Gallery: Simthsonian Institution.

ASHBROOK HARVEY Susan 2006, Scenting salvation. Ancient Christianity and the olfactory imagination, Berkeley, University of California Press.

AUBAIL-SALLENAVE Françoise 1998, «Bân, un parfum et une image de la souplesse : l'histoire d'un arbre dans le monde arabo-musulman », in Ryka GYSELEN (éd.), Parfums d'Orient, Bures-sur-Yvette, p. 9-27.

BEHRNAUER Walter 1861, «Mémoire sur les institutions de police chez les Arabes, les Persans et les Turcs », Journal asiatique XVIII/3, p. 1-240.

BlACHÈRE Régis, CHOUÈMI Moustapha et DENIZEAU Claude 1967-1976, Al-Kāmil. Dictionnaire arabe-françaisanglais (Langue classique et moderne), Paris, Maisonneuve et Larose.

BONNÉRIC Julie 2012, "Les huiles et leurs usages en terre d'Islam à partir du VII siècle », in Dominique FRÈRE et Laurent HUGOT (éd.), Les huiles parfumées en Méditerranée occidentale et en Gaule, VIII siècle av.-VIII siècle apr. J.-C., Rennes, Presses universitaires de Rennes, p. 307-314.

BOUBAKEUR Si Hamza 2003, Traité moderne de théologie islamique, Paris, Maisonneuve et Larose.

BUQUET Thierry 2015, « De la pestilence à la fragrance. L'origine de l'ambre gris selon les auteurs arabes », Bulletin d'Études Orientales LXIV, p. . 113-133.

CAlverley Edwin E. and Pollock James W. 2000, Nature, Man and God in Medieval Islam. 'Abd Allah Baydami's text Tawali al-Anwar min Matali al-Anzar, Leyde, E.J. Brill.

CANARD Marius 1951, «Le cérémonial fatimide et le cérémonial byzantin. Essai de comparaison », Byzantion XXI, p. 355-420.

CHEBEL Malek 1995, Dictionnaire des symboles musulmans, Paris, Albin Michel.

COULON Jean-Charles 2015, «Fumigations et rituels magiques. Le rôle des encens et fumigations dans la magie arabe médiévale », Bulletin d'Études Orientales LXIV, p. 179-248.

CRONE Patricia 1987, Meccan trade and the rise of Islam, Princeton, University Press.

DE GOEJEJan 1907, « L'encensement des morts chez les anciens Arabes », in Actes du XIV congrès international des orientalistes, Alger, 1905, Paris, Leroux, III, p. 3-7.

DiETRICH Albert 1983, « Lubān », in Encyclopédie de l'Islam (2éd.), Leyde, E.J. Brill, V, p. 792-793.

DiETRICH Albert 1988, Dioscorides Triumphans. Ein anonymer arabischer Kommentar (Ende 12. Jahrh. N. Chr.) zur Materia Medica, Göttingen, Vandenhoeck und Ruprecht.

Dols Michael W. et GAMAL Adil S. 1984, Medieval Islamic Medecine. Ibn Ridwân's Treatise « On the Prevention of Bodily Ills in Egypt », Berkeley, University of California Press.

DoNKIN Robin A. 1999, Dragon's Brain Perfume. An Historical Geography of Camphor, Leyde, E.J. Brill.

FEHRENBACH E. 1922 « Encens », Dictionnaire d'archéologie chrétienne et de liturgie, Paris, Librairie Letouzey et Ané, v, 1, col. 2-21.

GAST Marceau 1968, « Usage des encens dans le Sahara central », Libyca XVI, p. 171-174.

GAUDEFROY-DEMOMBYNES Maurice 1923, Le pèlerinage à la Mekke. Études d'histoire religieuse, Paris, Geuthner (Annales du Musée Guimet, Bibliothèque d'études 33).

GoITEIN Shelomo Dov 1983, A Mediterranean Society. The Jewish communities of the Arab world as portrayed in the documents of the Cairo Geniza, Vol. Iv: Daily Life, Berkeley, University of California Press.

Käs Fabian 2010, Die Mineralien in der arabischen Pharmakognosie, Wiesbaden, Otto Harrassowitz. 
KING Anya H. 2007, The musk trade and the Near East in the early Medieval period, Inpublished dissertation, Indiana University.

KING Anya H. 2010, «Tibetan musk and Medieval Arab perfumery », in Anna AKASOY, Charles BURNETT et Romit YoELI-TLALIN (éd.), Islam and Tibet. Interactions along the musk routes, Londres, Ashgate, p. $145-161$.

LANE Edward 1863-1893, An Arabic-English Lexicon, Édimbourg, Williams and Norgate, 8 vol.

LE MAGUER Sterenn 2015, «Une archéologie des odeurs : identifier les encens et leurs usages au Proche et Moyen-Orient (VIII ${ }^{\mathrm{e}}-\mathrm{XII}{ }^{\mathrm{e}}$ siècle) », Bulletin d'Études Orientales LXIV, p. 135-158.

LEV Efraim et ZOHAR Amar 2013, «Trends in the use of perfumes and incense in the Near East after the Muslim conquests », Journal of the Royal Asiatic Society 3/23, p. 11-30.

LEVEY Martin 1973, Early Arabic Pharmacology, Leyde, E.J. Brill.

LEWICKI Tadeusz 1984, «Les sources arabes concernant l'ambre jaune de la Baltique », Archaeologica Polona XXIII, p. 121-142.

MCHUGH James 2013, «Blattes de Byzance in India: Mollusk opercula and the history of perfumery », Journal of the Royal Asiatic Society 3/23, p. 53-67.

MEMON Muhammad Umar 1976, Ibn Taymiya's Struggle against Popular Religion, with an Annotated Translation of his Kitāb iqtị̄ā' aș-șirāt al-mustaqīm mukhālafat așhāb al-jahìm, Paris, Mouton.

Michot Jean 1978, «L'épitre d'Avicenne sur le parfum », Bulletin de philosophie médiévale 20, p. 53-57.

MiQUEL André 1980, La géographie humaine du monde musulman 3, Paris, Mouton.

RAYMOND André et WIET Gaston 1979, Les marchés du Caire. Traduction annotée du texte de Maqrīzī, Le Caire, Ifao.

RUSKA Julius et PLESSNER Martin 1960, «'Anbar », in Encyclopédie de l'Islam (2éd.), Leyde, E.J. Brill, I, p. 498-499.

SANAGUSTIN Floréal 1998 « Parfums et pharmacologie en Orient médiéval : savoirs et représentations », Res orientales XI, dossier thématique : Parfums d'Orient, Ryka GYSELEN (éd.), p. 189-202.

SAUVAGET Jean 1947, La mosquée omeyyade de Médine, Paris, Institut français de Damas.

TROUPEAU Gérard 1979, «Les fêtes des chrétiens vues par un juriste musulman », in Mélanges offerts à Jean Dauvillier, Toulouse, Centre d'histoire juridique méridionale, p. 795-802.

WiEDEMANN Eilhard 1913, «Aus Nuwairs Enzyklopädie Ueber Parfüms », Archiv für die Geschichte der Mathematik, der Naturwissenschaften und der Technik 6, p. 418-426.

WIEDEMANN Eilhard 1970, « Aus der arabischen Handels und Warenlehre von Abu'l Faḍl Ga far Ibn 'Alî al Dimaschqî », in Eilhard WIEDEMANN, Aufsätze zur arabischen Wissenschaftsgeschichte, Hildesheim, Olms Weidemann, II, p. 5-24.

WIEDEMANN Eilhard 1970a, «Über von den Arabern benutzte Drogen », in Eilhard WIEDEMANN, Aufsätze zur arabischen Wissenschaftsgeschichte, Hildesheim, Olms Weidemann, II, p. 230-274.

WigoDER Geoffrey (éd.) 1993, Dictionnaire encyclopédique du judaïsme, Paris, Éditions du Cerf. 